\title{
Meta
}

Journal des traducteurs

Translators' Journal

\section{The Wild Things in Japanese: Markedness, Rhythm and Cultural Acceptance}

\section{Dominic Cheetham}

Volume 56, numéro 3, septembre 2011

URI : https://id.erudit.org/iderudit/1008335ar

DOI : https://doi.org/10.7202/1008335ar

Aller au sommaire du numéro

Éditeur(s)

Les Presses de l’Université de Montréal

ISSN

0026-0452 (imprimé)

1492-1421 (numérique)

Découvrir la revue

Citer cet article

Cheetham, D. (2011). The Wild Things in Japanese: Markedness, Rhythm and Cultural Acceptance. Meta, 56(3), 596-609. https://doi.org/10.7202/1008335ar

\section{Résumé de l'article}

Le texte des albums illustrés est souvent d'une simplicité trompeuse. Comme le montre Riita Oittinen (2003) dans son analyse des traductions suédoise, allemande et finnoise de Where the Wild Things Are (1963) par Maurice Sendak, il peut être plus complexe ou plus soigneusement écrit qu'il ne paraît à première vue. Oittinen examine attentivement la longueur des phrases et la ponctuation en rapport avec le rythme de la lecture à haute voix. La présente étude reprend et étend son analyse pour la traduction japonaise. Cette traduction diffère de façon radicale du texte originel - bien plus que les traductions étudiées par Oittinen. La conclusion souligne que la traduction japonaise est néanmoins un texte populaire, qui connaît depuis longtemps de forts tirages au Japon. 


\title{
The Wild Things in Japanese: Markedness, Rhythm and Cultural Acceptance
}

\author{
DOMINIC CHEETHAM \\ Sophia University, Tokyo, Japan \\ c-domini@sophia.ac.jp
}

\begin{abstract}
RÉSUMÉ
Le texte des albums illustrés est souvent d'une simplicité trompeuse. Comme le montre Riita Oittinen (2003) dans son analyse des traductions suédoise, allemande et finnoise de Where the Wild Things Are (1963) par Maurice Sendak, il peut être plus complexe ou plus soigneusement écrit qu'il ne paraît à première vue. Oittinen examine attentivement la longueur des phrases et la ponctuation en rapport avec le rythme de la lecture à haute voix. La présente étude reprend et étend son analyse pour la traduction japonaise. Cette traduction diffère de façon radicale du texte originel - bien plus que les traductions étudiées par Oittinen. La conclusion souligne que la traduction japonaise est néanmoins un texte populaire, qui connaît depuis longtemps de forts tirages au Japon.
\end{abstract}

\begin{abstract}
The written text of picturebooks is often deceptively simple. However, as Riita Oittinen (2003) shows in her analysis of Swedish, German and Finnish translations of Maurice Sendak's Where the Wild Things Are (1963), picturebook text can be more complex, or more carefully written than it at first appears. Oittinen examines sentence length and punctuation in relation to rhythm for reading aloud. This study follows and extends her analysis for the Japanese translation. The Japanese translation is dramatically different from the original text - much more so than the translations studied by Oittinen. The conclusion highlights that the Japanese translation is nonetheless a very popular and long selling text within its target culture.
\end{abstract}

\section{MOTS CLÉS/KEYWORDS,}

album illustré, complexité, marques, poétique, Sendak picturebook, complexity, markedness, poetics, Sendak

\section{Introduction: Complexity, Rhythm and Changes}

Current research into the narrative techniques and implied audiences of picturebooks has shown very clearly that this particular area of art is not the simplistic, childish thing that stereotypes would suggest. The complex intertextuality of Janet and Alan Ahlberg's The Jolly Postman (1986), ${ }^{1}$ the experiments in viewpoint and reality in Jon Scieszka and Lane Smith's The True Story of the 3 Little Pigs (1989), ${ }^{2}$ the subtle changes in narrative voice in Anthony Browne's Voices in the Park (1998), ${ }^{3}$ all clearly demonstrate that picturebooks are, very often, very far from simplistic.

The texts listed above, and many others exampled in theoretical discussion of picturebooks (for example in Nodelman 1988; Nikolajeva and Scott 2006) are complex by nature of their text-illustration interactions, and their parodic and/or intertextual content. This type of complexity is both striking and marked. In situations where a markedly complex text is translated into a new culture, as with The Jolly 
Postman with its very noticeable intertextuality, it would be a very insensitive translator who failed to notice that complexity. Indeed, in cases like this, and as we specifically see in the Dutch translation of The Jolly Postman, translators often make great efforts to preserve the complexity of the original text (Desmet 2001).

Translators are reported to make any number of changes to fit what they perceive as the needs of the new target audience or culture. There are changes to create new intertextual references as mentioned above for The Jolly Postman (Desmet 2001); changes to fit concepts of morality or taboo as in the German translation of Pippi Langstrump (O'Sullivan 2005: 82-85); changes due to the cultural expectations of translation, as in the Danish translation of Dahl's Fantastic Mr Fox (Dollerup 2003: 97); changes towards a conventional style of translation, or what Puurtinen (2003) terms "translationese"; changes due to the stylistic norms of the target culture, as with the grammatical tense of Jean de Brunhoff's Histoire de Babar, ${ }^{5}$ when translated into English (Lathey 2006b); even changes in the perceived gap between the text and the pictures of a picturebook (O'Sullivan 2005: 122-124); and also, of course, changes introduced as a result of the constraints of the lexico-grammatical system of the target language.

Translators make many changes, partly for linguistic reasons, partly for cultural reasons, and, for children's literature, partly because of their concepts of child, or of children's literature itself. Changes made by translators can be condemned, applauded or simply reported, and the studies cited above do all of these. However, the basis of these changes is usually noticing; the translator notices something about the source text which they consider worth changing in their translation, and they actively make those changes for what they consider valid reasons.

But these are not the only changes. Sometimes the qualities of the original text are not so marked or noticeable, and these elements of a text may be lost simply because they, or their value, are not noticed, and they are sacrificed in order to satisfy some other aim of translation.

\section{Maurice Sendak: The Dominance of Visual Art}

Another powerful factor influencing the translation of picturebooks comes from perceptions about the relative value of the visual art and the verbal art, which together make up the text. Picturebooks selected for translation are often books which have achieved some sort of individual fame, or which are part of the total output of a well known author/illustrator. These books/authors are respected, but in the absence of noticeable complexity in the written text, might well be treated as examples of high quality or original artwork, or as attractive or compelling plot/plan, or non-linguistic content, but as having little poetic value to the actual writing. One example of an apparently, textually simple, picturebook, would be Where the Wild Things Are by Maurice Sendak. ${ }^{6}$

Because Maurice Sendak has produced illustrations for text written by other writers as well as illustrating his own texts, and probably also because of the quality and complexity of his illustrations, he has come to be seen as an artist rather than an author. Sendak is one of the most highly referenced artists in the academic discussion of picturebooks, but the discussion of his work is normally in relation to his pictures rather than to his writing. This view is repeated and reinforced by the number of 
books available presenting "the art of Maurice Sendak" to the general reading public, in relation to the relative absence of discussion of his writing style (see for example, Lanes 1980; Kushner 2003; Poole 1996). As such, Sendak's illustrations have come to be highly valued in translation, and it would be very unlikely that his illustrations would be modified in any way (except sometimes for the textual elements of illustrations), or even replaced by work from a different artist. No publisher of translations would even consider the possibility of producing a Where the Wild Things Are with different illustrations. This is, of course, not true of all texts released in translation. For texts where the writing is seen as the most valuable element, or where illustrations are seen as supplementary to the written text, illustrations are often replaced with new work for the new audience. Perhaps because Sendak is working in picturebooks, or perhaps because his reputation as an artist overshadows his reputation as a writer, the written text of the Wild Things is probably less valued in translation than are the illustrations, and consequently, complexity is less likely to be noticed.

\section{Analysis of Where the Wild Things Are}

\subsection{Marked Complexity}

The Wild Things does not contain any particularly noticeable intertextual reference, variation in viewpoint, parody, wordplay, or even any particularly complex language. Other factors which complicate translation for children, especially the presence of cultural referents or taboo, are also largely absent in the text, and as mentioned above, the perception of Sendak as an artist rather than as an author probably also reduces the noticeability of any other complexity in his written language.

Oittinen (2003: 135) argues that, "what is special in Sendak's book is the rhythm of the storytelling." Noticing the rhythmic qualities of a picturebook requires a sensitivity to rhythm, and also an appreciation of the value of rhythm in picturebooks. As such, the rhythmic qualities of a text, especially when it is not easily identifiable as poetic, are likely to be less noticeable, and thereby liable to loss or change in translation. Even in a European setting, translators may not always notice the read-aloud qualities of a text. Sometimes this will lead to a loss of those qualities, but sometimes translators manage to preserve them without necessarily being aware that they are doing so (Dollerup 2003: 82). Conceivably a cultural, linguistic or poetic closeness can sometimes balance out the problem of lack of noticing. An unconscious preservation of rhythmic features, while possible, is less likely to be the case in a Japanese translation, where the prosodic qualities of the target language and the poetic traditions of the target culture are very different to those of the source language and culture.

\subsection{Valuing Rhythm}

Oittinen (2003) gives us a comparative study of translations of the Wild Things in German, Swedish and Finnish. She does not dwell on the specific lexical and grammatical choices made by the various translators, but instead concentrates on some of the structural/graphological features of the text, and their relationship with rhythm, and the act of reading aloud. Lexico-grammatically simple picturebooks, such as the 
Wild Things, are written with a clear dual intended reader; first the child, who is the primary addressee; and second the adult, who will often have the role of reading the text aloud. Oittinen $(2003 ; 2004: 179 ; 2006$ : 93) argues that when a text written with reading aloud in mind is translated, the reading aloud qualities of the text are also important in the translation, a perspective strongly supported by Dollerup (2003) and Lathey (2006a: 10).

It should perhaps be stressed here that Oittinen does not argue for the primacy of the source text, and argues that translation is a re-writing and a re-creation of a text (see Oittinen 2004: 172; 2006: 84). She treats translation as a functional process whereby the translation should perform comparable functions in the target language/ culture as it does in the source. By arguing this, Oittinen argues in favour of lexicogrammatical and content change, provided that the changes serve to make the text function to the translator's intentions for the target language/culture. In examining the rhythmic qualities of the Wild Things she is critical of changes which reduce those qualities, presumably because rhythm is seen as having a powerful function in enhancing the read-aloud qualities of the text.

Oittinen argues that read-aloud rhythm is powerfully bound up in punctuation and sentence boundaries, stating that, "[t]hrough punctuation, like using commas and full stops, as well as sentence and word length, the translator gives visual hints to the aloud-reader when to stop and when to make haste" (Oittinen 2003: 132). This argument, if it needs support, can be compared with comments made by Ursula LeGuin, an author intensely interested in rhythm in literature. Speaking of the narrative sentence, she says, "[i]ts rhythm is part of the rhythm of the whole piece; all its qualities are part of the quality and tone of the whole piece" (LeGuin 1998: 39). And in relation to sentence length and punctuation, "[t]he poet Carolyn Kizer said to me recently, 'Poets are interested mostly in death and commas,' and I agreed. Now I add: Prose writers are interested mostly in life and commas" (LeGuin 1998: 31).

Rhythm and punctuation are serious topics for authors, and it is reasonable to suppose that they should be serious topics too, for translators, especially in a readaloud situation.

\subsection{Sentence Length and Distribution}

Oittinen, in her analysis, concentrates mainly on the balance of the sentence lengths and the punctuation which Sendak uses in his story, focusing particularly on the first half of the book. This paper widens the focus of the analysis, as the balance of sentence length across the whole book shows a symmetry which adds to the rhythmic qualities of the text.

Because sentence length and distribution are so important to this discussion, I have provided a breakdown in the following tables. The Wild Things is not paginated but I have given a page count in the tables. The text for each double spread is either to the left of the artwork, marked 'L' or below, marked 'BL' for the left side, or 'BR' for the right side.

The story starts with three long sentences taking us through: (i) the trouble Max makes, and his row with his mother; (ii) the transformation of his room and his journey across the seas to the land of the wild things; (iii) meeting the wild things, taming them, and becoming their king. 
TABLE 1

Breakdown of sentences (i)-(iv) of Where the Wild Things Are

\begin{tabular}{|c|c|c|c|c|}
\hline $\begin{array}{l}\text { Sentence } \\
\text { Number }\end{array}$ & Page Count & Lines of text & $\begin{array}{l}\text { Position of } \\
\text { Text }\end{array}$ & $\begin{array}{l}\text { Words per page } \\
\text { (per line) }\end{array}$ \\
\hline \multirow[t]{3}{*}{ (i) } & $1 / 2$ & 1 & $\mathrm{~L}$ & 13 \\
\hline & $3 / 4$ & 1 & $\mathrm{~L}$ & 2 \\
\hline & $5 / 6$ & 3 & $\mathrm{~L}$ & $22(6 / 7 / 9)$ \\
\hline Total & 3 spreads & & & 37 words \\
\hline \multirow[t]{5}{*}{ (ii) } & $7 / 8$ & 1 & $\mathrm{~L}$ & 9 \\
\hline & $9 / 10$ & 1 & $\mathrm{~L}$ & 2 \\
\hline & $11 / 12$ & 2 & $\mathrm{~L}$ & $16(8 / 8)$ \\
\hline & $13 / 14$ & 2 & $\mathrm{~L}$ & $19(11 / 8)$ \\
\hline & $15 / 16$ & 3 & $\mathrm{~L}$ & $17(6 / 5 / 6)$ \\
\hline Total & 5 spreads & & & 63 words \\
\hline \multirow[t]{5}{*}{ (iii) } & 17 & 2 & $\mathrm{BL}$ & $22(12 / 10)$ \\
\hline & 18 & 1 & BR & 10 \\
\hline & 19 & 2 & $\mathrm{BL}$ & $12(5 / 7)$ \\
\hline & 20 & 2 & $\mathrm{BR}$ & $23(10 / 13)$ \\
\hline & 21 & 1 & $\mathrm{BL}$ & 8 \\
\hline Total & 2.5 spreads & & & 75 words \\
\hline (iv) & 22 & 1 & $\mathrm{BR}$ & 9 \\
\hline Total & 1 page & & & 9 words \\
\hline
\end{tabular}

Sentences (i), (ii) and (iii) show a progressive increase in length so that sentence (iv), which spans only one line of one page, and uses just nine words, has an incredibly abrupt and dramatic feel:

(1) “And now," cried Max, "let the wild rumpus start!"

(Sendak 1963: 22)

Following sentence (iv), there are three double page spreads with illustrations only, showing the "wild rumpus." The next page (29) has two sentences, (v) and (vi), of 15 and 21 words respectively, sharing three lines of text (12/13/11 words per line). The facing page has a single sentence (vii) of 27 words over three lines. These pages mark the end of Max's time in the place where the wild things are. When we turn the page again, Max is back in his boat, and there are only two sentences of the story left: (viii) the wild things ask Max to stay; (ix) the wild things roar and ask him not to go, Max sails back the way he came to his room where his supper is waiting.

\section{TABLE 2}

Breakdown of sentences (vii)-(ix) of Where the Wild Things Are

\begin{tabular}{|c|c|c|c|c|}
\hline $\begin{array}{l}\text { Sentence } \\
\text { Number }\end{array}$ & Page Count & Lines of text & $\begin{array}{c}\text { Position of } \\
\text { Text }\end{array}$ & $\begin{array}{l}\text { Words per page } \\
\text { (per line) }\end{array}$ \\
\hline (vii) & 30 & 3 & BR & $27(9 / 6 / 12)$ \\
\hline Total & 1 page & & & 27 words \\
\hline (viii) & 31 & 3 & BL & $21(9 / 8 / 4)$ \\
\hline Total & 1 page & & & 21 words \\
\hline \multirow[t]{4}{*}{ (ix) } & 32 & 3 & $\mathrm{BR}$ & $32(12 / 10 / 10)$ \\
\hline & $33 / 34$ & 3 & $\mathrm{~L}$ & $16(6 / 6 / 4)$ \\
\hline & $35 / 36$ & 2 & $\mathrm{~L}$ & $17(9 / 8)$ \\
\hline & $37 / 38$ & 1 & $\mathrm{~L}$ & 5 \\
\hline Total & 1 page and 3 spreads & & & 70 words \\
\hline
\end{tabular}




\subsection{Rhythm and Symmetry}

Sendak appears to be actively using sentence length as a stylistic tool. The marked variation in sentence length and the symmetrical distribution of those varying lengths before and after the central pivot of the illustration-only pages gives a long, slow, wavelike rhythm to the whole book. Accompanying this is a progressive increase in the size of the pictures over the first part, until in the central double-spreads the pictures take up the entire double page. This is followed by the progressive shrinking of the pictures in the end part of the book. This change in picture size is described by Schwartz as "the compositional rhythm of the expanding visual space as Max withdraws from reality and arrives, in fantasy, at omnipotence and then returns to reality, with the pictures contracting again, and a blank page on which the story ends" (Schwartz 1982: 18).

Framed within the rhythmic symmetry of the sentence length and the picture size, we also find symmetry of textual repetition and symmetry of movement, to and from the place where the wild things are. The presence of multiple symmetries paralleling that of sentence length shows that it is very unlikely that the variation in sentence length is accidental.

\subsection{Poetic Features}

Sendak repeatedly introduces line breaks for reasons other than the simple prose convention of reaching the edge of a page. This creative use of line breaks is to be found with all the sentences of the book, and if we look at the number of words per line, we find a rough equality which, if read aloud, shows clearly that these divisions are motivated by rhythm.

Sendak does not use commas at all in this text, except where they are conventionally necessary before speech marks, as in "And now," cried Max, "let the wild rumpus start!" (sentence [iv]). He uses line breaks as a partial replacement for commas, introducing line breaks where a comma might be a more conventional choice for a prose text. Oittinen does not explicitly state so, but it is clear that Sendak is using some of the techniques more commonly associated with poetry than with prose, and is notably using some of the orthographic techniques of poetry. Indeed, in Sendak's own poetry for children, he makes the same choice of ending lines without using commas (Sendak 1962a; 1962b $^{7}$.

Sendak is not alone in using poetic techniques in children's prose. Milne in his Winnie-the-Pooh stories, and Hughes in The Iron Man, both make use of poetic techniques, including orthographic techniques, to enhance the effect of their work (Cheetham 1999). Indeed, when we look at picturebooks in general, we find that poetic techniques, and especially the orthographics of poetry, are very commonly used, and often create a rhythmic, musical effect, or "musicality" (Heald 2007). The intensification of the rhythmic aspects of a work, which these techniques produce, is an effect which is especially powerful with Where the Wild Things Are.

It might also be noted that many of the academic discussions of the Wild Things, when quoting the text, use the diagonal slash, the conventional symbol for a line change in poetry, to denote the line changes in the text: "The night Max wore his wolf suit and made mischief of one kind / and another /." 


\section{Oittinen's Findings in The Wild Things Translations}

Analysing the use of sentence breaks and commas in the German, Swedish and Finnish translations, Oittinen finds that for sentence (i), both the Finnish and German translations split the sentence - the German with two commas, and the Finnish with a full stop. For the second long sentence, the German translation adds four commas, and one full stop. The Swedish translation adds three commas, but no full stops. The Finnish translation only adds one comma, and no full stops.

With regard to the positioning of the line breaks, Oittinen only mentions that the German translation makes a different division between pages 1 and 2 of sentence (i) such that:

(2) The night Max wore his wolf suit and made mischief of one kind and another

(Sendak 1963: 1-2)

becomes

(3) An dem Abend, als Max seinen Wolfspelz trug und nur Unfug im Kopf hatte,

(Sendak 1963, translated by Claudia Schmölders 1967:1-2; quoted in Oittinen 2003: 136)

This change moves the first mention of Max's mischief to the second page, causing a mismatch between the text and the art-work. The German translation also makes other changes to the distribution of the line breaks. For example, on page 13:

(4) and an ocean tumbled by with a private boat for Max and he sailed off through night and day

(Sendak 1963: 13)

becomes

(5) Und plötzlich war da ein Meer mit einem Schiff, nur für Max, und er segelte davon, Tag und Nacht

(Sendak 1963, translated by Claudia Schmölders 1967: 1-2; quoted in Oittinen 2003: 137)

Two lines become three lines, clearly changing the rhythm. And although Oittinen does not mention it, the translation has also reversed the order of night and day producing a disruption of the temporal rhythm of the text. For the Swedish and Finnish translations, no changes to the line breaks are evident from Oittinen's published data.

Finally, Oittinen criticizes the German translation for making unnecessary changes to the wording of the text, as for example, in the Und plötzlich seen in the example above. This not only changes the rhythm of the text, but influences the whole character of the text making the sequence less "like a dream but more logical" (Oittinen 2003: 137). For Oittinen the dreamlike quality of the sequence is a product of both the wording and of the long, smooth, unbroken form of the text. As such, a change in the text which decreases the dreamlike quality can be seen to have a knock on effect in reducing the smooth rhythmical effects of the orthographics. 
We could add a similar criticism of the inserted line nur für Max, which makes the rather covert statement of a private boat into a more overt use of a narrator's voice which is consciously using more child-directed language. This change makes the narrator intrusive, which also serves to break up the flow of the words. Overall, the Swedish and Finnish translations are seen as more clearly preserving the rhythm of the text, albeit with significant changes from the original.

\section{The Japanese Translation}

There are two Japanese translations of the Wild Things. However, for this study we only examine Teruo Jingu's 1975 translation, ${ }^{8}$ which supersedes the 1966 Uezahiru translation ${ }^{9}$ (Takahashi 2008), and is now the best known version, and the only Japanese translation commonly available.

For the first sentence of Teruo Jingu's translation, five commas and one full stop are added, with the single original sentence split into two sentences. This split is significant, because with only one change in a single verb ending (おこった[okotta] to おこって[okotte]), a full stop would not have been necessary. This is therefore a translating choice rather than a linguistic necessity. The second sentence has a total of 13 added comas, and the single sentence is split into five sentences by the addition of four full stops - considerably more subdivision than in any of the translations discussed by Oittinen.

For the first sentence the number of lines per page is the same as in the original. The second sentence, however, has a change on its fifth and final page (p. 15); the page which gives us the most obviously poetic layout and the three short, clipped, rhythmically balanced phrases of Max's journey:

(6) and in and out of weeks

and almost over a year

to where the wild things are.

(Sendak 1963: 15)

（7）1しゅうかんすぎ、2しゅうかんすぎ、

1 shuukan sugi, 2 shuukan sugi, ひとつきふたつき ひがたって、

hitotsuki futatsuki higa tatta, 1ねんと1にちこうかいすると、

1 nento 1 nichi koukaisuruto, かいじゅうたちのいるところ。 kaijyutachino irutokoro.

(Sendak 1963, translated by Teruo Jingu 1975: 15)

Over 1 week, over 2 weeks,

through one month two months, sailing over a year and a day to, the place where the wild things are.

(Translated by the author)

The addition of this one line extends and changes the rhythm rather than actually breaking it, but like the German translation, logic and predictability are increased. In this case, increased by the addition of months to the original progression of (night and day) weeks, year. The logic and the concreteness are also made stronger by the 
change to concrete numbers, and the numerical progression of both the weeks and months. Finally, almost over a year becomes over a year and a day and firmly links Max's adventure with the European fairytale tradition, a link which Sendak has clearly avoided. The motivation for this change is unclear, especially in a translation which otherwise tends to domesticate the text, but it does strengthen the emphasis on exact time-spans, as opposed to Sendak's vague motion through ambiguous periods of time, and thereby further reduces the dreamlike qualities of the text.

Oittinen's analysis ended with these two opening sentences, and for the Japanese translation we can also mostly end in the same position. The remainder of the translation follows the same pattern of significant addition of commas and frequent breaking up of sentences, and need not be reported in detail.

However, sentence length and use of commas are not the only contributors to the rhythmic qualities of the written text. There are also the symmetrical aspects of the text, and the positioning of the line breaks.

The symmetry of the text is an important part of the form, and hence, the rhythm of this text, and one of the most striking examples of this symmetry is that when Max returns home after giving up being king of the wild things, the timing of his journey is also reversed (sentence [ix]):

(8) and sailed back over a year and in and out of weeks and through a day

(no text on p. 34)

into the night of his very own room

(Sendak 1963: 33-35)

In the Japanese translation though, this reversal does not happen. The three lines of p. 33 are translated with exactly the same wording as the first three lines of p. 15 (quoted above), showing an un-reversed sequence of weeks, months and a year and a day.

The first line of the next page (p. 35) does not mention "the night of his very own room," but reads:

(9) いつのまにやら、おかあさんにほうりこまれたじぶんのしんしつ itsunomaniyara, okaasanni hourikomareta jibunno shinshitsu. [some vague interval of time / by his mother / locked up / his own / bedroom.]

(Sendak 1963, translated by Teruo Jingu 1975:35)

after a while, his own bedroom, where his mother had locked him up.

(Translated by the author)

Not only is the sequence of time not reversed, but the arrival back into the night is lost. The reversal of the time sequence in the original, because it is so clearly an important part of the symmetry of the text, is also an important element to the overall rhythm and patterning of the text, and its loss produces a clear loss of rhythm in the Japanese translation, as does the loss of night as part of that time sequence.

Textual symmetry is also found elsewhere in the text, as with the psychologically crucial I'll eat you up (p. 5) and We'll eat you up (p. 31). The translation here gives lexically dissimilar phrases, thus further reducing the symmetry and rhythm of the text. Other examples of textual symmetry, however, are mostly preserved in the translation, and so the overall loss may not be very large. 
With respect to the positioning of line-breaks, the Japanese translation generally follows the example of the original, but the balance of the length of lines on a page is often less visually or aurally clear than in the original.

The Japanese translation has clearly failed to maintain the rhythmic features of sentence length, punctuation, a portion of the textual symmetry, and the balance of line-breaks found in the original text.

Other rhythmic features, such as the changes in picture size and the symmetry of movement obviously remain unchanged. Also, the new form of short sentences with many commas, while it does remove the original rhythm, replaces it with a new rhythm of it's own. The new rhythm, unlike the original, is not in symmetry with the pictorial rhythm, the rhythm of movement, or the flow of the story, nor does it have the "dreamlike" quality admired by Oittinen, but it still has a rhythm, which may possibly be attractive to the new audience.

\section{The Japanese Context}

Oittinen discusses European/Scandinavian translations of the Wild Things. Because of the relatedness of the languages or cultures involved, she can make assumptions about the perception and value of the rhythm in the target texts. However, in dealing with a translation from English to Japanese, where the language, the culture, the poetic traditions, and even the writing systems are very different, we cannot necessarily make such assumptions. Three questions therefore need to be considered: i) is it possible to replicate these long sentences in the Japanese language? ii) is it permissible in Japanese writing to print the text without commas? iii) if the original rhythm of the text is reproduced in Japanese, does it still have any poetic value for Japanese readers?

\subsection{Sentence Length}

Japanese has a different phrase order to English, having an SOV sequence. This can certainly cause problems in translating long sentences, especially when they need to correspond with sequences of illustration. This may be part of the reason for the large number of sentences in the Japanese translation. However, several of the sentence breaks in the translation are clearly the translator's choice rather than a linguistic necessity, as the okotta, okotte example stated above shows. It is certainly possible to write the story smoothly in Japanese using the original sentence patterning, and the choice to change sentence length is probably not a result of linguistic constraints.

\subsection{Commas}

The use of commas in Japanese, as in English, shows a great deal of inter-personal variation. If treated purely as prose, a lack of commas in the text would be very unusual in both Japanese and English. But if treated as a poetic form, the lack of commas is a perfectly normal thing in Japanese, especially in the haiku form, where commas are conventionally not used (Miner 1979: x). 


\subsection{Japanese Poetics}

I have argued that the style of the Wild Things has much in common with English language poetry, especially for orthographic features such as punctuation, line-breaks and textual layout, and also in terms of textual repetition and the rhythmic balance of the lines in the text.

Japanese poetry is very different to English language poetry, but remarkably, many of the common features of Japanese poetry are present in the text of the Wild Things. As with the Wild Things, Japanese poetry does not make much use of alliteration, rhyme, or predictable stress counts for lines, and makes less use of the stanza than does English language poetry (Kawamoto 2000: 173-221).

Haiku and tanka are well known to have fixed syllable counts for each line, but less formally fixed Japanese poetry commonly relies on a similar syllable count between lines, and/or a cyclic or sometimes symmetrical balance to the syllable counts (see for example the poetry of Kenji Miyazawa). This kind of patterning, and the effects it creates, is very close to what we find with the line lengths in the Wild Things.

Haiku uses a three part pattern, and if we look at the line counts for the different pages of the Wild Things, we find that 3 is a common number, making it visually, and sometimes rhythmically, very similar to haiku. The three part pattern is not exclusive to haiku and its specific syllable counts, and is also found in other discourse forms, such as in Japanese children's spoken stories (Minami and McCabe 1991).

Other features, such as textual repetition or symmetry are perfectly normal to Japanese poetry or prose.

In short, the aspects of the Wild Things which give it a closeness to English language poetry, also give it a closeness to Japanese poetry, possibly a closer similarity to Japanese forms than to English, and there is no reason to suppose that the techniques of the original would not have poetic value for Japanese readers.

\section{Conclusion: Reception of the Translation in Japan}

This analysis follows and extends Oittinen's analysis of the German, Swedish and Finnish translations of Sendak's the Wild Things in relation to Teruo Jingu's Japanese translation. Comparison shows us that Jingu's translation fails to reproduce the long sentences, has ignored Sendak's technique of replacing commas with line-breaks, has moved away from the forms of poetry, and has also introduced textual changes which further reduce the rhythmical qualities for reading the story aloud.

As discussed above, these changes are probably not a result of linguistic, stylistic or poetic differences between Japanese and English, and the question, is therefore begged, as to the possible sources of the changes.

It is very unlikely that the translator broke up the long sentences and added commas simply by accident. It follows, then, that the changes were made from choice. The conventional causes of such change in translating children's literature generally, and picturebooks specifically, are discussed above, and include such things as: the translator's own concepts of picturebooks and picturebook audience; a perceived lower value for the verbal text in relation to the visual text; pressure to conform to the unwritten conventions of Japanese translation for children; or even a cultural or 
personal belief that short sentences, amply signposted by commas, are easier for very young children to read. Such changes are made according to a kind of hierarchy of perceived importance. For example, if the rhythmical qualities of the sentences were seen as very important, they would stand a greater chance of being preserved in a translation. Indeed, if the translator only noticed the sentence length and punctuation, and failed to notice their rhythmical qualities, sentence length and punctuation are likely to be given a much lower value than if their rhythmical functions were also noticed.

Because of the degree of change in the Japanese translation, it is possible that the translator failed to fully notice the rhythmical effects of the original. In the present day this might be considered a failing, but we must remember that in 1975, when this translation was made, the academic study of picturebooks was in its infancy. Noticing requires some form of markedness, and, as in this case, if that markedness is not strong in the text alone, it requires background knowledge to focus attention or expectation. As literary study advances, and as translation study advances, translators might be expected to be more likely to notice a greater variety of textual effects, including the rhythmical effects of many works of children's literature, but with translations made prior to such advances, it is less reasonable to expect translators to notice the less marked qualities of texts such as the rhythm of sentence length or poetic styles in an English language picturebook.

In short, while the changes appear on the surface to be a textual loss, they are quite possibly motivated by perceived gains in other areas, or else are a result of a simple failure to notice relatively unmarked stylistic functions.

Despite the changes to the rhythm, we have the irrefutable fact that this translation, since its first publication in 1975, has been, and still is, a continually best selling picturebook. Obviously the people who buy the text and then read it aloud still find it a perfectly attractive text. Indeed, when my Japanese students are invited to discuss the translation they often see no problem with the changes, dismiss their significance, and are very positive about the translation as it stands.

It may be that a more rhythmically faithful translation would have found even more success with Japanese people, but that is now impossible to test. For the majority of Japanese people, this translated text is, of course, the text, and because of its popularity, any alternative translation would, ironically, be seen as a deviation from, or even an insult to, a well-loved book. Despite the changes made by the translator (and there are many other changes not directly connected with rhythm, and thereby not discussed in this paper) the Wild Things in Japanese translation is a successful text and, in that sense, the translation has successfully engineered the transfer of the text from one cultural setting to another. This may be a function of other strengths in the book, it may be that the translation has rendered the text into a new style or rhythm attractive to Japanese readers, or it may simply be that the rhythmical functions of sentence length and punctuation are less important to the overall impact of the book, at least for Japanese readers, than both Oittinen and this paper have argued.

\section{NOTES}

1. Ahlberg, Janet and Ahlberg, Allan (1986): The Jolly Postman or Other People's Letters. London: Heinemann.

2. Scieszka, Jon and Smith, Lane (1989): The True Story of the 3 Little Pigs. London: Penguin. 
3. Browne, Anthony (1998): Voices in the Park. New York: DK Publishing.

4. DAhL, Roald (1970): Fantastic Mr Fox. London: George Allen and Unwin.

5. DE Brunhoff, Jean (1931): Histoire de Babar. Paris: Hachette.

6. Sendak, Maurice (1963): Where The Wild Things Are. London: Harper Collins.

7. Sendak, Maurice (1962a): Chicken Soup With Rice: A book of Months. New York: HarperTrophy. Sendak, Maurice (1962b): Pierre: A Cautionary Tale. New York: HarperTrophy.

8. SENDAK, Maurice (1975): Kaijyutachinoirutokoro (かいじゅうたちのいるところ) [Where the Wild Things Are]. (Translated by Teruo Jingu) Tokyo: Fuzambo Publishing.

9. SENDAK, Maurice (1966): Iruiruobakegasundeiru (いるいるおばけがすんでいる) [Where the Wild Things Are]. (Translated by Uezahiru Translation Committee) Tokyo: Uezahiru Publishing.

\section{REFERENCES}

Cheetham, Dominic (1999): The Poetics of Pooh. English Literature and Language. 36:101-113.

Desmet, Mieke K. T. (2001): Intertextuality / Intervisuality in Translation: The Jolly Postman's Intercultural Journey from Britain to the Netherlands. Children's Literature in Education. 32(1):31-43.

Dollerup, Cay (2003): Translation for Reading Aloud. Meta. 48(1-2):81-103.

HeALD, Robin (2008): Musicality in the Language of Picture Books. Children's Literature in Education. 39(3):227-235.

Kawamoto, Kõji (2000): The Poetics of Japanese Verse. (Translated by Stephen Collington, Kevin Collins and Gustav HeldT) Tokyo: University of Tokyo Press.

Kushner, Tony (2003): The Art of Maurice Sendak. New York: Abrams.

LAnes, Selma G. (1980): The Art of Maurice Sendak. New York: Abrams.

LAthey, Gillian, ed. (2006a): The Translation of Children's Literature. Clevedon: Multilingual Matters.

LATHEY, Gillian (2006b): Time, Narrative Intimacy and the Child: Implications of Tense Switching in the Translation of Picture Books into English. In: Gillian LATHey, ed. The Translation of Children's Literature. Clevedon: Multilingual Matters, 134-141.

LeGuin, Ursula K. (1998): Steering the Craft. Portland Oregon: The Eighth Mountain Press.

Minami, Masahiko and McCABE, Allyssa (1991): Haiku as a Discourse Regulation Device: A Stanza Analysis of Japanese Children's Personal Narratives. Language in Society. 20(4):577599.

Miner, Earl (1979): Japanese Linked Poetry: An Account With Translations of Renga and Haiku Sequences. Princeton: Princeton University Press.

Nikolajeva, Maria and Scotт, Carole (2006): How Picturebooks Work. New York/London: Routledge.

Nodelman, Perry (1988): Words About Pictures: The Narrative Art of Picture Books. Athens: University of Georgia Press.

Oittinen, Riitta (2003): Where the Wild Things Are: Translating Picture Books. Meta. 48(1-2):128141.

Oittinen, Riitta (2004): Change and Renewal: Translating the Visual in Picture Books. In: Thomas VAn DER WALt, ed. Change and Renewal in Children's Literature. Westport: Preager, 171-181.

Oittinen, Riitta (2006): The Verbal and the Visual: On the Carnivalism and Dialogics of Translating for Children. In: Gillian Lathey, ed. The Translation of Children's Literature. Clevedon: Multilingual Matters, 84-97.

O'Sullivan, Emer (2005): Comparative Children's Literature. New York/London: Routledge.

Poole, L. M. (1996): Maurice Sendak and the Art of Children's Book Illustration. Maidstone: Crescent Moon Publishing.

Puurtinen, Tiina (2003): Genre-specific Features of Translationese? Linguistic Differences Between Translated and Non-translated Finnish Children's Literature. Literary and Linguistic Computing. 18(4):389-486. 
Schwartz, Joseph H. (1982): Ways of the Illustrator: Visual Communication in Children's Literature. Chicago: American Library Association.

TAKahashi, Akiko (2008): Mou hitotsu no Sendaku (もうひとつのセンダック) [A Different Sendak]. E hon Gakkai (絵本学会) [The Association for Studies of Picture Books]. Visited on 16 November 2009, <http://www.u-gakugei.ac.jp/ ehon/cn10/cn32/pg617.html>. 